Article

\title{
Systems Engineering Approach to Food Loss Reduction in Norwegian Farmed Salmon Post-Harvest Processing
}

\author{
Mohd Abualtaher*(D) and Eirin Skjøndal Bar \\ Department of Biotechnology and Food Science, NTNU-Norwegian University of Science and Technology, \\ 7491 Trondheim, Norway; eirin.bar@ntnu.no \\ * Correspondence: mohd.h.m.abualtaher@ntnu.no; Tel.: +47-9682-2638
}

Received: 1 December 2019; Accepted: 20 January 2020; Published: 27 January 2020

\begin{abstract}
The United Nations 2030 Agenda for Sustainable Development set the target of halving per capita global food waste and reducing food losses, including post-harvest losses. Food loss is a significant global challenge rising from the decrease in food quantities available for human consumption because of decisions and actions taken by food manufacturers and suppliers before it even reaches the retail market. Food loss within the Norwegian farmed salmon post-harvest processing system could be reduced by making change in the system's behavior. This study, by following systems engineering principles, aimed to develop insight into the salmon post-harvest processing system's behavioral dynamics causing current food loss and to consider conceptual keys to solutions. This study tied the food loss problem to systemic behavior of byproducts downgrading to non-food uses as the major cause. The decisions made on the materials flow are based on product design, quality control, and environmental solutions. Making a decision to conserve byproduct materials by prioritizing keeping them within the human food chain requires supportive data on their true potential as a food source. The system's information pool that decision makers rely on can be fortified with the system's engineering multidisciplinary outcomes that will enable the necessary paradigm shift to achieve the quested food loss reduction.
\end{abstract}

Keywords: Atlantic salmon; byproducts; post-harvest processing system (PHPS)

\section{Introduction}

The United Nations food and agriculture organization reported that one third of the global food production goes for waste, an estimated annual worth of 1 trillion USD, and environmental costs of 3.3 Giga-tons of greenhouse gas emissions [1]. In seafood production, the estimated loss is about $35 \%$ of the total production. Such a high loss has a multiple negative impact on food security, economy and environment [2]. Sustainable development goal (SDG) number 12: Responsible consumption and production; set the target number 12.3 that aims, by 2030, to reduce by half the global food waste per capita at the retail, consumer levels and reduce food losses along production and supply chains, including post-harvest losses. Setting up such a target by the United Nations reflects a global consensus on the significance of the problem, importance of the target and the achievability of this target. Food losses are the commonly used term to describe the decrease in edible human food material throughout the part of the supply chain that is designated specifically to produce food for human consumption such as food production systems and postharvest processing systems [3]. The post-harvest processing system (PHPS) is a set of activities applied on the output material of an agricultural production system not limited to plant production but including all kinds of animal production systems such as meat, dairy, bees-honey, aquaculture and fisheries. Post-harvest 
activities are dependent on the nature of the product but commonly include transportation, storage, sorting, processing, packaging and delivery to retail. PHPSs are structured on several elements that work together and aim to convert the received material into a human food product, safe for consumption, with nutritional content and market value. Any change requested from PHPS to optimize efficiency, adjustment of practice or adapting to a new paradigm requires by a complete analytical understanding of the system, the logic it is operating under and its influencing circumstances. Moreover, resources allocation through the PHPS can draw a clear picture of the system's performance. System metabolism of the material through processes and practices determines the size of food losses. Systems understanding can result in a set of qualitative and quantitative information on existing food losses and points of adjustments for their reduction.

The harvested food material flowing through the PHPS starting as a raw material and ending up as product go through transformational technical processes. The system treats the material according to several requirements: feasibility, quality standards, available technology, environmental demands and health restrictions. This necessitates a multidisciplinary approach for understanding the dynamics that influences the system and material. Therefore, any counter approach that overlooks the diverse sources of information that governs the systems behavior is not expected to result a holistic solution that appeals to the variable interests of the system's stakeholders. Consequently, it is not expected to overcome the systems homeostasis nor achieve the desired adaptation.

\subsection{Norwegian Salmon Farming (Background Information)}

Atlantic Salmon (Salmo Salar) production value chain in Norway is a mature industry that started in 1970. It has earned a pioneering economical role and high social significance as a national source of income, global contributor to the seafood market and aquaculture technology development. At the same time, it is operating in a governmentally well protected environment and conserves natural resources. Salmon is a main commodity in the Norwegian food market and for export as well.

The aquaculture production sector in Norway is regulated toward profitability, competitiveness and sustainable development [4]. The framed salmon value chain starts from salmon feed production used for salmon aquaculture and finally, the PHPS of the harvested salmon, as Figure 1 demonstrates.

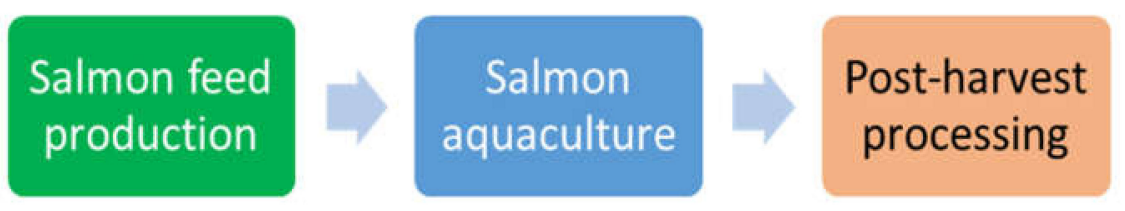

Figure 1. Norwegian farmed salmon value chain.

Aquaculture is the fastest growing food production sector in the world and Norway is the second major exporter of fish and seafood products to the global market [5,6]. In 2018, Norway exported 2.5 million tons of seafood (salmon, trout, cod, clip fish, herring, king crab, prawns, and mackerel) with a revenue of 90 billion NOK [7]. In 2017, Aquaculture exports revenue was 61.5 billion NOK [8] where $94.5 \%$ of the Aquaculture production was Salmon [7]. The quantity of the harvested salmon in 2018 was 1,281,872 tones [7]. Salmon aquaculture is an intensive production system based on biotechnology science [9] and it aims to produce nutritious seafood for human consumption. Since its beginning in 1970, the development of this industry has been a persevering endeavor carried out by multiple institutions that has continuously addressed environmental impact challenges and sustainable development. The wide involvement of establishments and stakeholders, ranging from private sector companies to academic institutions, regulative authorities, research institutions, associations, and global institutions, creates diverse contribution to the pool of knowledge in relation to the sustainable development of this sector. Norway is committed to the global Agenda 2030 for Sustainable Development and its 17 Sustainable Development Goals (SDGs), through the deployment of resources and efforts to make the desired changes and achieve the goals as assured by the Norwegian government 
in the official agenda 2030 follow-up statements. Food waste reduction falls at the heart of SDGs 2 and 12 [10].

From the previous research, it is clear that Salmon aquaculture production in Norway has a well-monitored cost, both environmental and financial, leading to the conclusion that the harvested Salmon is a worthy biomass and the demands for it to be efficiently processed and utilized to the maximum level are reasonable from several perspectives. However, a major portion of the harvested Salmon mass does not end up as food products [2,11-13] but instead, as waste material or processing by-products that, in the best cases, go to other non-food uses and can be counted as a food loss.

\subsection{Food Loss Reduction Challenge}

The United Nations made a global commitment for the 17 sustainable development goals to be achieved by the year 2030, in a global platform known as Agenda 2030. Sustainable development goal number 12 (SDG 12) is responsible consumption and production by ensuring sustainable consumption and production patterns. Under SDG 12 falls target 12.3 (Table 1); which aims, by 2030, to halve per capita the global food waste at the retail and consumer levels and to reduce food losses along food production and supply chains, including post-harvest losses. The target is specified by the measurable indicator 12.3.1-Global food losses, which has two sub-indicators 12.3.1, including the Food Loss Index (FLI), which focuses on food losses that occur from production up to (and not including) the retail level and measures the changes in percentage losses for a basket of 10 main commodities by country in comparison with a base period, and sub-indicator 12.3.1 b, which measures Food Waste, which comprises the retail and consumption levels. Both sub-indicators will contribute to measuring progress in reducing food loss and food waste toward achieving SDG target 12.3.

Table 1. Summary of UN 2030-Agenda related terms used in this study.

\begin{tabular}{cl}
\hline UN 2030-Agenda & $\begin{array}{l}\text { Global transformation toward sustainability } \\
\text { 17 Sustainable Development Goals (SDGs) }\end{array}$ \\
\hline \multirow{2}{*}{ SDG 12 } & $\begin{array}{l}\text { Ensure sustainable consumption and production patterns } \\
\text { This goal is interpreted to 11 Targets. }\end{array}$ \\
\hline \multirow{2}{*}{ Target 12.3 } & $\begin{array}{l}\text { Halve per capita global food waste at the retail and consumer levels and reduce } \\
\text { food losses along production and supply chains, including post-harvest losses. } \\
\text { Target has one measurable indicator on its performance; that subdivides for two } \\
\text { sub indicators. }\end{array}$ \\
\hline \multirow{2}{*}{ Indicator 12.3.1 } & Sub-indicator A-Food Loss Index (FLI), Production \\
\cline { 2 - 2 } & Sub-indicator B-Food Waste Index (FWI) Retail \& consumption \\
\hline
\end{tabular}

The scope of this study is focused on food loss reduction at the post-harvest processing stage. The UN agenda 2030 in general, and target 12.3 specifically, provide general guidance on addressing the food loss problem and achieving targeted reduction. Reviewing target 12.3 specifications provided accurate definition for the problem and clarified distinctions between the different categories of food waste. Target 12.3 suggested some guiding concepts to approach this challenge, such as that it is a system-level problem, measuring material and change needs to be holistic, and considerate to the system's stakeholders and the three elements of sustainability (environment, economy and society). The definition of (PHPS) food loss applies to not only the losses in final food product intended for human consumption but also the associated inedible parts, which usually depart the human food supply chain as by-products. Target 12.3 is equally concerned with food security and resource-use efficiency [14]. The targeted reduction, if achieved, could help in addressing the food production-associated environmental impacts and contribute to hunger relief through a higher efficiency of the agri-food systems [15]. Food loss does not only decrease the quantity of available food for human consumption but also lowers the availability of the natural resources required to produce food. This fact is becoming more important with time due to the growth of the world population, which is estimated 
to be more than $30 \%$ increase by the year 2050 [16]. The reduction of post-harvest loss can advance the sustainability of the food value chain from economic, social, and environmental perspectives [17]. Food loss in the production segments of the food supply chain is caused either by the way in which the production system functions or its institutional and legal framework [18]. Defining food loss causing practices requires measurements for quantities tied to each practice or process. Causes relevant to the institutional and legal framework require understanding of the social and economic context; moreover, defining the involved stakeholders and allocating causes with their sources.

A study conducted on food losses and the potential for reduction in Switzerland found that $48 \%$ of the total calories produced are lost across the whole food value chain. The study emphasized the need for solution to avoid food losses. However; the implementation of solution measures requires all "actors" to be involved, including the government [19]. Some of the defined causes for food losses are associated with poor infrastructure and logistics, lack of technology, insufficient skills, knowledge and management capacity of supply chain actors, lack of access to markets and natural disasters [20]. Solutions that involve changing attitudes, behaviors, technologies, developing policies, strategies and initiatives to address the issues of food loss must be done in collaboration with the relevant stakeholders that influence decisions or are affected by decisions. The different aspects considered in the context of Food loss reduction are industrial, commercial, and institutional. Any solution will concern all the involved in processing, preparing, preserving, distributing, and serving or selling food products, governmental agencies with responsibilities related to food, environment, agriculture, public health and social development. Nongovernmental Organizations (NGOs) that work on food loss reduction, researchers; both within and outside of academia [21]. Post-harvest loss reduction was found to be associated with several issues that are considered locally and globally relevant to economic development and social welfare. Moreover, issues like food security, food safety, economic revenues, employment in the food sector, and climate footprint are relevant when considering solutions to the problem. Those issues were found to have a strengthening effect on the post-harvest management in general and positively support mobilizing resources for the target of post-harvest food loss reduction [22]. From the previous research, we conclude that the food loss reduction challenge expands vertically from local, regional, national and global levels. In addition, it expands widely horizontally over multiple sectors, institutions and stakeholders. The weight of the problem was proven to be heavy and costly. Conclusively, the problem is systemic, and any resolution requires analyzing the causes within the system and developing amendments to the system. Systems engineering is the discipline concerned with systems analysis and development. Material control falls in the core definition of the problem and the targeted change must be based on efficient and proper usage of that material and its applicability to food loss and food waste [23,24].

This study discusses food loss reduction in a farmed salmon post-harvest processing system in Norway from systems engineering perspectives, aiming to

1- Gain a wide-covering insight into salmon PHPS through systems engineering.

2- Identify the causative elements in material transformations within the PHPS.

3- Discuss how to cause the desired adaptation; food loss reduction? A scheme for change that serves to achieve target 12.3 .

\section{Methodology: Systems Engineering}

Systems engineering is defined by the international Council on Systems Engineering (INCOSE) as a "transdisciplinary and integrative approach to enable the successful realization, use, and retirement of engineered systems, using systems principles, concepts, scientific, technological, and management methods" [25]. Systems engineering is the discipline concerned with the system as a whole; it emphasizes its design, construction and operation considering economical structures, environment, technology, and its interactions with other systems [26].

The system's interacting functions and elements require a holistic evaluation of the variations in the system's structure [27]. Systems are a collection of hardware, software, people, facilities, and procedures 
organized to accomplish some common objectives that stakeholders of the system are interested in [28,29]. Systems engineering principles can guide toward understanding an industrial system and gain insight into its structure and behavior [30]. System engineering allows to address the system's interacting elements in relation to the targeted problem or quested development. The understanding of a comprehensive system requires: recognizing the multidisciplinary nature of the system's components, defining the stakeholders who contribute to the decisions that direct the system, and describing the system's behavioral dynamics. Analytical system understanding will help in problem formulation, revealing its causes, suggesting actionable measures, and the reassessment for the efficiency and consequences of the applied set of measures. In summary, a system engineering framework structured based on the three main concepts of requirements, behaviors, and structures [26] expected to result from the system functional configuration in Figure 2.

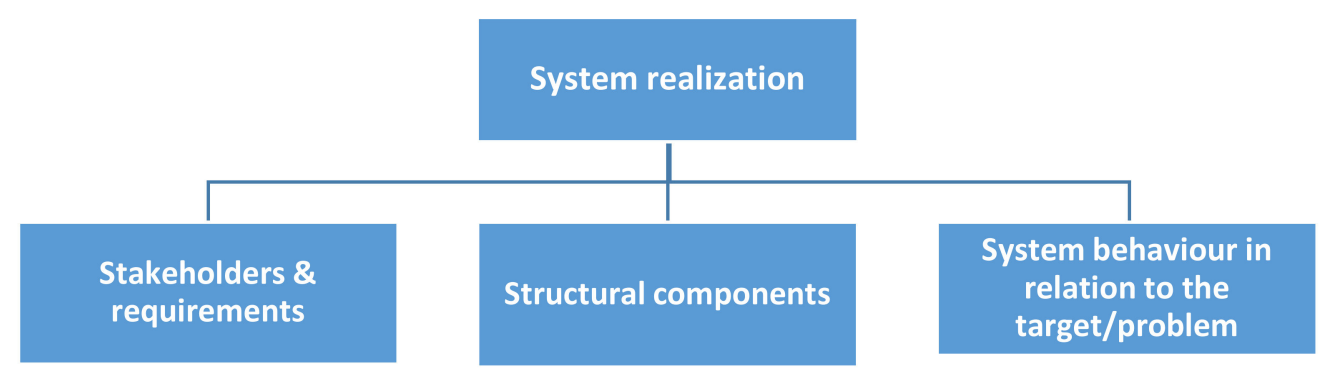

Figure 2. Conceptual map for a system understanding framework.

\subsection{System's Stakeholders}

When identifying the stakeholders of a system, those who maintain the system, are involved in its development, influenced by its outcomes and can influence the system's behavior are fundamental. Moreover, this is a vital step in approaching the targeted problem, the developmental quests, and eventually, reaching a functioning resolution. Any adjustment that aims to bring the system closer to the target must appeal to the interests and avoidances of the stakeholders. The stakeholders organize and carry out the maintenance, regulation and development of the system. The stakeholders are identified to be included and represented in the decision-making process that will formulate a solution for the problem; in this case, the food loss reduction target. Food production and food loss concern diverse groups and touch different interests. For this reason, a multi sectoral approach is needed to identify the stakeholders due to the wide civic engagement in directing and governing food systems, as it is a vitally impactful sector on society's health, economy, livelihood and welfare. Moreover, the food system is structured on sub systems and activities of multiple sectors such as agriculture plant production, animal production, post-harvest processing, food industry, food retail and services.

Defining the stakeholders in the development process of the food post-harvest industrial system within the context of Sustainable development goals (SDG) must reflect the inclusion of the three pillars of sustainability Environment, Economy and society as system requirements, starting from the innovation stage, as Figure 3 illustrates.

In addition, food systems and their impacts expand over multiple levels, including local, regional, national, international and global. The inclusion principle applies to stakeholders from multiple sectors and multiple levels of impact, ranging between local small pressure groups all the way to global United Nations institutions (Table 2). 


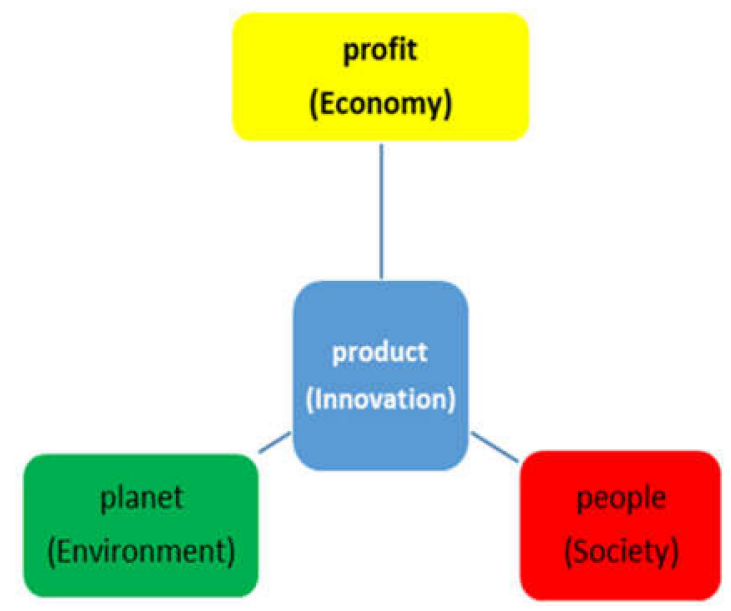

Figure 3. Sustainable Product innovation model published by Delft University of Technology and UNEP [31].

Table 2. Food systems stakeholders' interests and type of involvement.

\begin{tabular}{ccc}
\hline Stakeholder & Interest & Involvement \\
\hline Private sector & revenue & ownership and management \\
Academia & Science, development & research \\
Public health governance & Food safety, community nutrition & Inspection and guidance \\
Env. authorities & Environmental protection. & Inspection and guidance \\
Local NGOs & Social agenda & Info., Ethics, pressure groups. \\
Global institutions (UN/FAO) & SDG/2030 Agenda & contribute to info. /ideas \\
\hline
\end{tabular}

The inclusion concept translates, in practice, to communication with the Stakeholders, to identifying their requirements, interests and avoidances in relation to the addressed problem and targeted solution. Any suggested solution will have costs and benefits, consecutively, and it will face resistance by those who might bear cost or more responsibility with more chance to be embraced by the beneficiaries. The socio-economical context that PHPS are operating within imposes commitment for environmental protection and highlights the economical contributions of this sector in generating revenue and employment opportunities. A social agenda for relevant ethics and its associated regulations are critically vital elements of the system, for example, animal welfare, gender equality, child labor, GMOs and corporate social responsibility. Moreover, sustainability is becoming more of a social demand and a global mission.

\subsection{Systems Structural Components}

Partitioning the system into functional and physical building blocks is a means to configure the system's functions, manage its interfaces and develop its capabilities [26]. Each building block (structural component) corresponds to a body of knowledge that is tied to a discipline of science or a credible source of information. PHPS is structured on physical and functional components that serve the delivery of the designed product. PHPSs are composed of physical elements of material, machinery, labor, and energy. Functional components include procedures, quality standards, food safety systems, measures for compliance with environmental regulations, and legal restrictions. Physical and functional components work together to produce a food product fit for human consumption that can compete in the market. The components of the system studied and developed by various disciplines of science and management include Food technology, Human Nutrition, mechanical engineering, Industrial Hygiene, Industrial ecology, Quality assurance management, Production management, social sciences and Business administration. The targeted problem of food losses in a PHPS has several aspects not limited to the applied technical expertise and process management but also has to do with the commercial profit margins, legislations and social trends. The targeted problem needs to be addressed 
in an interdisciplinary manner to cover the environmental aspects, economics, social and cultural perspectives. Just as food science and technology is the discipline of science that is specialized in food products, qualities and processing, other disciplines of science cover the other concerns and aspects of the problem.

The system's complex dynamics can be understood further by deconstructing it to its basic components and associated body of knowledge (Table 3). Food losses are not only lost human nutrients but also lost natural resources and environmental stressors; they impact the climate with a higher carbon footprint, negatively affect biodiversity, cause more lost water, more stress on land use and surface water hypertrophy [32]. Food loss is a system performance indicator and a challenge for research and development. Any suggested solution needs to first review relevant legislations and social cultural acceptance. All these multidisciplinary perspectives of the problem of food loss flow through the system as information that decides the system's behavior.

Table 3. Structural components and associated disciplines of a post-harvest processing system (PHPS).

\begin{tabular}{cc}
\hline Element of the System & Associated Discipline \\
\hline Human Food material & Food Technology + Human Nutrition \\
Product development (R\&D) & Food Technology + Engineering \\
Quality criteria & Food Technology + Quality assurance management \\
Machinery and automated production & Mechanical Engineering \\
Food safety & Food Technology + (HACCP based systems) \\
Environmental impacts & Industrial Ecology + LCA + EMS (ISO 14001) \\
Costs and revenue & Business administration+ Marketing + industrial management \\
Social responsibility & Social science + Decision making framework+ diverse info. pool \\
\hline
\end{tabular}

\subsection{System's Behavior}

A system's behavior is the materialization of the assembled structural components, and a descriptive term for the outcome performance, results and choice of practices. A system's form and operations are based on numerous decisions made to insure the system's functionality [27]. A system's decisions are always based on information; the background collective knowledge that shapes the system, defines the flowing material and governs the system's actions (Figure 4).

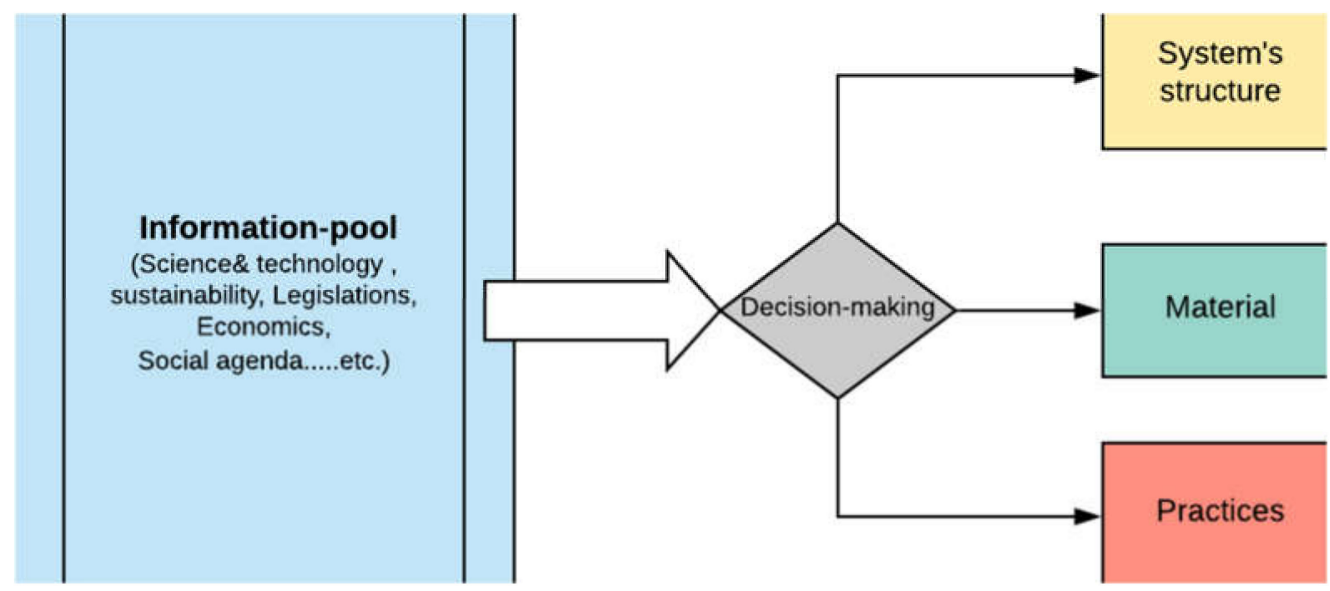

Figure 4. Information, terms and paradigms guide the system's behavior.

The information obtained from multiple disciplines lay the technical foundation that system processes are structured upon, including the terms and descriptions of the material processed by the system at the different stages of production. This material description determines the attitude of the system toward the processed input material and the output material in every process. The terms usually reflect the system's major interest or liability in association with material at each stage; weather 
it relates to cost, performance, quality, safety, or environmental impacts. Food losses are commonly described by the system as scrap, trimmings, non-edible parts, quality non-compliant, and that decides the following action taken by the system. Actions on material that cause food loss are usually regrading/downgrading that material, reprocessing it in limited cases, transferring it to a different processing system or discarding it. Material description or classification is based on measurements taken by the system for the purpose of control, either quantitative or qualitative. The decision maker support actions on material according to the paradigm of how to reduce, reuse or recycle. Materials that are not included by the product design cannot be reduced or reused in the same process; for example, peels off vegetables or guts, skin and bone from animal material. Consequently, these are dealt with as waste material, which is an environmental problem that requires a waste management solution.

\section{Salmon Post-Harvest Processing System (System's Understanding)}

System components: The post-harvest processing system is structured based on queued technical activities applied on the input material such as slaughtering, bleeding, cleaning, quality control, nutritional value measures, skinning, storage, deboning, and processing (Figure 5). In Norway, this industry is automated to an advanced level and has minimum dependence on human labor compared to fish processing systems anywhere else in the world. The system is supported by logistical activities: transporting, marketing, information and communication, administration and management. Processes include primary processing of slaughtering and de-gutting and secondary processing of filleting, fillet trimming, portioning, and producing different cuts like cutlets. Further processing might be applied in some factories and might include smoking, making ready meals or Packing with Modified Atmosphere (MAP). Products that have been secondarily processed are called value-added products (VAP). For the scope of this study, we focus on the Salmon fillet, as it is the major and final Salmon product.

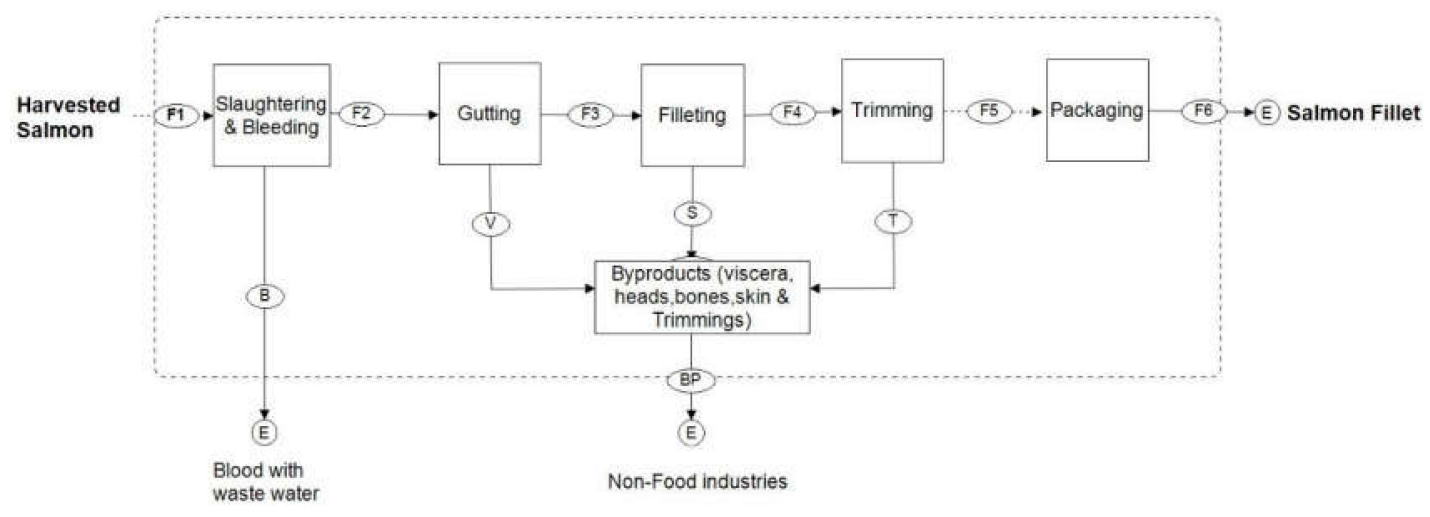

Figure 5. Salmon post-harvest processing system flow chart.

Stakeholders: (involved, affected socially, economically and environmentally) any outcome suggestions must consider their interests and avoidances. In the Norwegian context, it is important to highlight the clear harmonious flow of information and to share perspectives between the different stakeholders in a structured manner. This structured flow is very available in this case due to the fact that the farmed salmon industry in Norway encounters development challenges and limitations with Norwegian government-sponsored/led research and innovation endeavors [33,34]. The Norwegian government is committed to the Agenda 2030 Sustainable Development Goals, including food loss and food waste reduction targets [35]. Academic research in Norwegian universities and research institutions points to a trend in investigating the utilization of the harvested salmon biomass, optimum usage of the byproducts and the rest of the raw material [2,11,36,37].

System's behavior: The system's behavioral attitude toward the material is driven by product design. As the final product will be Salmon fillet, it considers the blood, head, skin, fins, bones and viscera as excluded material. During processing strict quality control, standards and food safety restrictions applied on the material, any material that is found to be not compliant for any reason will 
be excluded and marked out as scrap material (Figure 6). The salmon PHPS made a shift from being heavily manual labor-based to automation of the processing lines applying modern technology [38,39]. Automation increased the production rate and efficiency with the material, reducing the amount of scrap or delay-caused-spoilage. In the process of Salmon fillet production, the estimated ratio of the extracted marketable product compared to the input harvested biomass could reach $50 \%$ in most optimum conditions, leaving the other excluded $50 \%$ of the biomass out as a waste material that is being managed to eliminate its environmental consequences and slightly recover part of its costs. A fundamental question arises: why does this study see this excluded material of heads, skin, blood, viscera and trimmings as food being lost? The answer is because of its significant load of nutrients and its absence of any extraordinary hazards. These fish organs and remaining raw material are eaten by people in certain markets and culinary cultures [40].

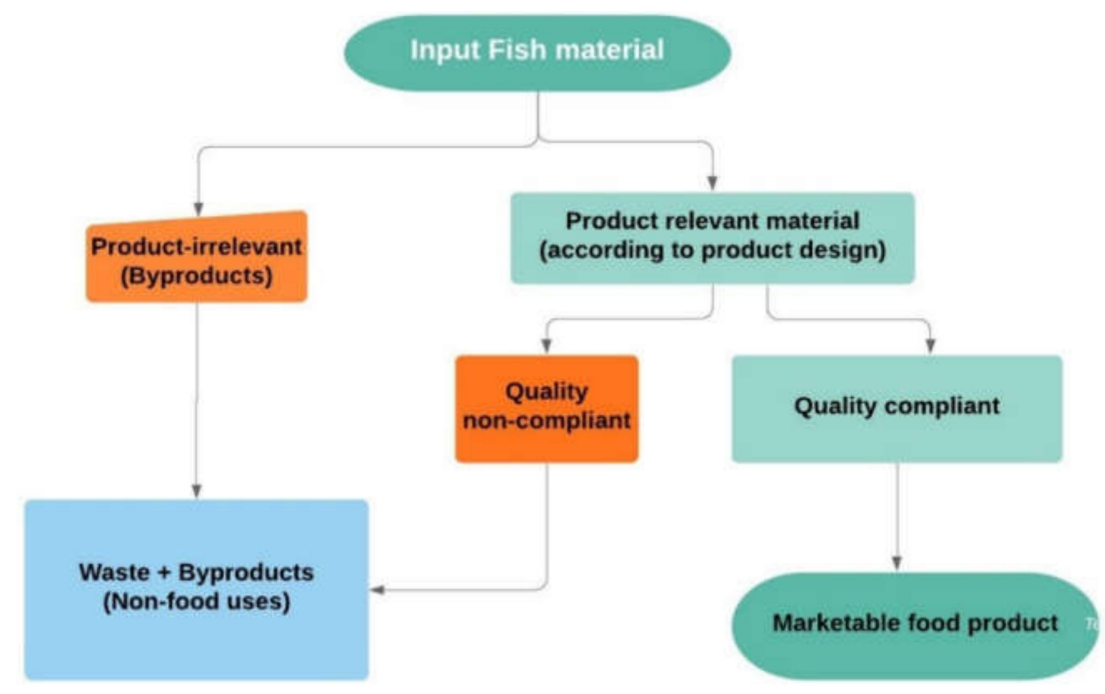

Figure 6. Salmon post-harvest processing system and basic material classification.

As the system operates under strict environmental regulations, proper waste management is necessary, due to the waste material being hydrolyzed and turned to silage that is transferred to non-food industries, including but not limited to the fur animals and pet feed industry to be used as a feed ingredient. Such a practice might somehow serve the concept of material circularity from economic and ecological perspectives. However, salmon is a resource-costly fish to grow in all aspects, and for pet feed, there are much less costly alternatives. Downgrading the salmon byproducts to become pets' feeding ingredients might involve taking part of this material far from its true potential as quality human food. Salmon biomass contains plenty of valuable nutrients, vital to human health in high concentrations like vitamins (B12, B3, B6 and D), essential fatty acids (Omega 3) and trace mineral (selenium, iodine, phosphorous) [41-43]. Those vital nutrients are not only present in the fillet product, they are also in the rest of the biomass that is turned to byproduct material. Targeting the post-harvest excluded material to restore those nutrients back to the human food chain will raise nutrients availability for the nutritional challenged global society [44] and conform to the UN Sustainable Development Goals 2 and 12.

\section{Discussion: How to Achieve the Targeted Food Loss Reduction?}

To serve the desired system's adaptation of less food loss, a change in the systems behavior and a paradigm shift are needed. Moreover, supportive data on quantities of lost food material are needed to highlight its nutritional content and reveal its human food potential. Awareness of this materials load of nutrients and the costly resources consumed to produce it will lead to a shift in the paradigm from describing the by-product biomass material as waste to as a secondary source. Secondary sources can become food ingredients in a new human food product. The nutritional content of secondary 
sources should be revealed and communicated to the concerned stakeholders as proof of its significant potential as a human food and a source for community nourishment. In addition, the monetary cost and the carbon footprint of the secondary output material both are measurable parameters that need to be highlighted and presented for the decision makers who are seeking to maximize the revenue and to minimize eco-impacts through the most feasible and efficient use of this worthy material. Research and development endeavor to develop new food products by turning all the remaining raw material to quality, marketable food products as a starting point. Alternative scenarios based on allocating responsibility of minimum food loss to the PHPS will demand a change from the current material downgrading measures toward a status of multiple production lines for diverse food products within the same factory. The advanced level of automation that Norwegian Salmon PHPSs have reached can potentially allow further processing of the remaining raw material to become food products without being labor shortage-limited or -dependent. Minimum waste production without shifting the responsibility for the material to another non-food system will guarantee a higher harvested biomass to food conversion ratio. Usually, the material that is classified as a production ingredient is handled with care; its cost and quality are controlled in a standardized manner. The inclusion of byproducts as human food ingredients is a necessary step to facilitate such a fundamental transition.

At the operational level, output waste material is classified either as non-compliant with quality control standards, or as not part of the final product design, commonly described as not edible or not marketable. However, it is possible to change that classification and its associated system's behavior by highlighting the nutritional content and potential revenue of this excluded material. The current practice of ensiling the salmon by-products (Enzymatic hydrolysis) lowers the proteins quality and quantity in the produced silage material $[12,45]$. Salmon proteins are very high-quality animal proteins and they are costly synthesized within the aquaculture production system. The ensiling process deconstructs material that was intentionally constructed by a previous anthropogenic system; a sign of contradictive work and a waste of resources. Data has supported the need for the system's decision makers to reconsider the material downgrading decision. The synergy between the salmon PHPS and non-food industries like the fur animals feed, fertilizers, or bioenergy industries must be questioned on the basis of prioritizing the conservation of nutrients within the human food chain. The use of salmon byproducts in the feed industry is a fit environmental circularity solution with economic benefit to reuse waste material instead of disposing of it. On the other hand, this by-product material carries a significant load of nutrients and the legislations do not prohibit its usage as human food if compliant to health restrictions, as with the rest of the fish anatomy. This dual fitness for food and feed brings a legitimate question of prioritizing. Recycling byproducts from the food process to the feed process out of the human food chain could appear as an easy waste management solution, but that does not serve the growing human population needs for food and nutrients. Thus, a regulated disengagement between the food and feed industries might be a reasonable idea and a legitimate suggestion. Achieving a salmon PHPS with minimum food loss is an added value that appeals to the interests of all the system's stakeholders (Table 2), starting with the private sector earning more revenue from costly raw material, gaining technological advancement of the industry and improving operational efficiency. The societal interests in food security, efficient utilization of natural resources and community nutrition would all benefit from turning the underutilized material of salmon byproducts into food. For the governmental stakeholder and the global stakeholder, who are both committed to the food loss reduction target, such a transition in a major commodity value chain would be a step closer toward achieving a set target.

\section{Conclusions}

A system's engineering approach to food loss reduction in farmed salmon PHPSs has provided a holistic understanding of the system and brought attention to a wide range of practicalities that need to be considered to reach the quested change. This study accomplished its objectives by developing insight into the salmon PHPS, identifying what drives the material transformations within the salmon 
PHPS and discussing scenarios with required system adaptations to result in food loss reduction. This study stresses the need to prioritize keeping nutrients within the human food chain as a key concept in addressing this issue. Terms and classifications that define the processed material can embrace this perspective by defining the output material based on its nutritional content. This will reveal to the decision maker the true potential of the by-product material as food. The relationship between the PHPS and the preceding production systems, salmon feed and salmon aquaculture, should be considered to present the environmental and economic costs of this biomass to avoid its downgrading to non-food uses. The synergy with the feed industry and bioenergy industry needs to be reevaluated in the shadow of prioritizing human food needs. The main contribution of this study is the qualitative description of the system and the relevant concepts presented in addressing the food loss challenge. The main limitation of this study rises from the need for a quantitative description of the material flowing through the salmon PHPS. The exact quantity of the material being downgraded to non-food, its actual content of nutrients and monetary costs is a gap in the knowledge that this study did not fill. Based on that limitation, we suggest that further studies apply quantitative methods for a material inventory and analysis. The material flow analysis methodology could serve that purpose and overcome this limitation.

Author Contributions: The article was primarily written and conceptualized by MA. where EB supervised the research, reviewed and edited the article as part of a doctoral program. All authors have read and agreed to the published version of the manuscript.

Funding: This research received no external funding.

Acknowledgments: All needed resources for this study were provided by The Norwegian University of Science and Technology (NTNU); acknowledged with appreciation and gratitude.

Conflicts of Interest: The authors declare no conflict of interest.

\section{References}

1. The Food and Agriculture Organization of the United Nations (FAO). Available online: http://www.fao.org/ $\mathrm{nr} /$ sustainability/food-loss-and-waste (accessed on 5 July 2019).

2. Abualtaher, M.; Bar, E.S.N. Review of applying material flow analysis-based studies for a sustainable Norwegian Salmon aquaculture industry. J. Appl. Aquac. 2019. [CrossRef]

3. Parfitt, J.; Barthel, M.; Macnaughton, S. Food waste within food supply chains: Quantification and potential for change to 2050. Philos. Trans. R. Soc. B Biol. Sci. 2010, 365, 3065-3081. [CrossRef]

4. Aquaculture-Act. Act of 17 June 2005 No. 79 Relating to Aquaculture. Available online: https://www. fiskeridir.no/English/Aquaculture/Aquaculture-Act (accessed on 15 August 2019).

5. The Food and Agriculture Organization (FAO). The State of World Fisheries and Aquaculture 2018-Meeting the Sustainable Development Goals; CC BY-NC-SA 3.0 IGO; FAO: Rome, Italy, 2018.

6. The Food and Agriculture Organization (FAO). The State of World Fisheries and Aquaculture 2016; Contributing to Food Security and Nutrition for All; FAO: Rome, Italy, 2016; p. 200.

7. SBB. 2018. Available online: https://www.ssb.no/en/jord-skog-jakt-og-fiskeri/statistikker/fiskeoppdrett/aarforelopige (accessed on 20 August 2019).

8. $\quad$ Ernst \& Young. The Norwegian Aquaculture Analysis 2017; Ernst \& Young: London, UK, 2017.

9. The Organisation for Economic Co-operation and Development (OECD). Atlantic Salmon (Salmo Salar), in Safety Assessment of Transgenic Organisms in the Environment: OECD Consensus Documents; OECD Publishing: Paris, France, 2017.

10. Ministries. Norway's Follow-Up of Agenda 2030 and the Sustainable Development Goals; Norwegian Government: Oslo, Norway, 2016. Available online: https:/www.regjeringen.no/en/dokumenter/follow-up-sdg2/ id2507259/ (accessed on 10 July 2019).

11. Rustad, T. Maximising the Value of Marine By-Products (Chapter Physical and Chemical Properties of Protein Seafood By-Products); CRC Press Woodhead Publ.: Boca Raton, FL, USA, 2007.

12. Ramírez, A. Salmon By-Product Proteins; Food and Agriculture Organization of the United Nations (FAO): Rome, Italy, 2007. 
13. Sierra Lopera, L.M.; Sepulveda Rincon, C.T.; Vasquez Mazo, P.; Figueroa Moreno, O.A.; Zapta Montoya, J.E. Byproducts of Aquaculture process: Development and prospective uses. Vitae 2018, 25, 128-140. [CrossRef]

14. Lipinski, B.; Hanson, C.; Lomax, J.; Kitinoja, L.; Waite, R.; Searchinger, T. Reducing food loss and waste. World Resour. Inst. Work. Paper 2013.

15. Bengtsson, M.; Alfredsson, E.; Cohen, M.; Lorek, S.; Schroeder, P. Transforming systems of consumption and production for achieving the sustainable development goals: Moving beyond efficiency. Sustain. Sci. 2018, 13, 1533-1547. [CrossRef] [PubMed]

16. Wunderlich, S.M.; Martinez, N.M. Conserving natural resources through food loss reduction: Production and consumption stages of the food supply chain. Int. Soil Water Conserv. Res. 2018, 6, 331-339. [CrossRef]

17. Raut, R.D.; Gardas, B.B.; Kharat, M.; Narkhede, B. Modeling the drivers of post-harvest losses-MCDM approach. Comput. Electron. Agric. 2018, 154, 426-433. [CrossRef]

18. Liu, B. Case Study Methodology to Find the Causes of Food Loss and Develop Solutions; FAO, Nutrition and Food Systems Division: Rome, Italy, 2016; pp. 13-23.

19. Beretta, C.; Stoessel, F.; Baier, U.; Hellweg, S. Quantifying food losses and the potential for reduction in Switzerland. Waste Manag. 2013, 33, 764-773. [CrossRef]

20. Eggersdorfer, M.K.K.; Cordaro, J.B.; Fanzo, J.; Gibney, M.; Kennedy, E.; Labrique, A. 4 Food Loss and Waste: The Potential Impact of Engineering Less Waste; Good Nutrition: Perspectives for the 21st Century; Karger Publishers: Basel, Switzerland, 2016.

21. Commission for Environmental Cooperation. Characterization and Management of Food Loss and Waste in North America; Commission for Environmental Cooperation: Montreal, QC, Canada, 2017; p. 48.

22. Gogh, B.V.; Boerrigter, H.; Noordam, M.; Ruben, R.; Timmermans, T. Post-Harvest Loss Reduction: A Value Chain Perspective on the Role of Post-Harvest Management in Attaining Economically and Environmentally Sustainable Food Chains; Wageningen Food \& Biobased Research: Wageningen, The Netherlands, 2017.

23. Risku-Norja, H.; Maenpaa, I. MFA model to assess economic and environmental consequences of food production and consumption. Ecol. Econ. 2007, 60, 700-711. [CrossRef]

24. Padeyanda, Y.; Jang, Y.-C.; Ko, Y.; Yi, S. Evaluation of environmental impacts of food waste management by material flow analysis (MFA) and life cycle assessment (LCA). J. Mater. Cycles Waste Manag. 2016, 18, 493-508. [CrossRef]

25. International Council on Systems Engineering (INCOSE). Available online: https://www.incose.org/ (accessed on 13 September 2019).

26. Kossiakoff, A.; Sweet, W.N. Systems Engineering: Principles and Practices; Wiley Online Library: Hoboken, NJ, USA, 2003.

27. Raz, A.K.; Kenley, C.R.; DeLaurentis, D.A. System architecting and design space characterization. Syst. Eng. 2018, 21, 227-242. [CrossRef]

28. Buede, D.M. The Engineering Design of Systems: Models and Methods; Wiley: Hoboken, NJ, USA, 2011.

29. Buede, D.M. Introduction to Systems Engineering. In The Engineering Design of Systems; Buede, D.M., Ed.; John Wiley \& Sons, Inc.: Hoboken, NJ, USA, 2008; Chapter 1; pp. 1-48.

30. Arnold, R.D.; Wade, J.P. A Definition of Systems Thinking: A Systems Approach. Procedia Comput. Sci. 2015, 44, 669-678. [CrossRef]

31. UNEP; DUoTa. Design for Sustainability; United Nations Environment Programme (UNEP): Nairobi, Kenya, 2009.

32. The Food and Agriculture Organization (FAO). Food Wastage Footprint, Impacts on Natural Resources; FAO-United Nations: Roma, Italy, 2013. Available online: http://www.fao.org/sustainable-food-valuechains/library/details/en/c/266219/ (accessed on 6 October 2019).

33. Asche, F.; Guttormsen, A.G.; Tveterås, R. Environmental problems, productivity and innovations in Norwegian salmon aquaculture. Aquac. Econ. Manag. 1999, 3. [CrossRef]

34. Chu, J.J.; Anderson, J.L.; Asche, F.; Tudur, L. Stakeholders' Perceptions of Aquaculture and Implications for its Future: A Comparison of the USA and Norway. Mar. Resour. Econ. 2010, 25, 61-76. [CrossRef]

35. Affairs, N.M.O.F. Norway's Follow-Up of Agenda 2030 and the Sustainable Development Goals; Norwegian Government: Oslo, Norway, 2016.

36. Skara, T.; Sivertsvik, M.; Birkeland, S. Production of salmon oil from filleting byproducts-Effects of storage conditions on lipid oxidation and content of omega-3 polyunsaturated fatty acids. J. Food Sci. 2004, 69, E417-E421. [CrossRef] 
37. Opheim, M.; Slizyte, R.; Sterten, H.; Provan, F.; Larssen, E.; Kjos, N.P. Hydrolysis of Atlantic salmon (Salmo salar) rest raw materials-Effect of raw material and processing on composition, nutritional value, and potential bioactive peptides in the hydrolysates. Process Biochem. 2015, 50, 1247-1257. [CrossRef]

38. Bar, E.S. A case study of obstacles and enablers for green innovation within the fish processing equipment industry. J. Clean. Prod. 2015, 90, 234-243.

39. Bar, E.; Mathiassen, J.R.; Eilertsen, A.; Mugaas, T.; Misimi, E.; Linnerud, A.S.; Salomonsen, C.; Westavik, H. Towards robotic post-trimming of salmon fillets. Ind. Robot 2016, 43, 421-428. [CrossRef]

40. Eurofish International Organisation. Fish entrails and processing waste as a raw material. Eur. Mag. Issue, 2 April 2019.

41. Rembold, C.M. The health benefits of eating salmon. Science 2004, 305, 475. [CrossRef]

42. Jacob Exler, P.R.P. Nutrient Content and Variability in Newly Obtained Salmon Data for USDA Nutrient Database for Standard Reference; US Department of Agriculture: Washington, DC, USA, 2007.

43. Atanasoff, A.; Nikolov, G.; Staykov, Y.; Zhelyazkov, G.; Sirakov, I. Proximate and mineral analysis of Atlantic salmon (Salmo Salar) cultivated in Bulgaria. Biotechnol. Anim. Husb. 2013, 29, 571-579. [CrossRef]

44. Initiatives, D. Global Nutrition Report: Shining a Light to Spur Action on Nutrition; WHO: Geneva, Switzerland, 2018.

45. Arason, S. Production of Fish Silage in Fisheries Processing: Biotechnological Applications; Chapman \& Hall: London, UK, 1994; pp. 244-272.

(C) 2020 by the authors. Licensee MDPI, Basel, Switzerland. This article is an open access article distributed under the terms and conditions of the Creative Commons Attribution (CC BY) license (http://creativecommons.org/licenses/by/4.0/). 